\title{
Percepção dos profissionais da saúde sobre aspectos da gestão da informação no processo de planejamento do Sistema Único de Saúde.
}

\section{Perception of health professionals about aspects of information management in the planning process of the Unified Health System.}

\section{Percepción de los profesionales de la salud sobre aspectos de la gestión de la información en el proceso de planificación del Sistema Único de Salud.}

\author{
Fernanda Bergamini Vicentine ${ }^{1}$ \\ Thatiane Delatorre ${ }^{2}$ \\ Milton Roberto Laprega ${ }^{3}$ \\ Janise Braga Barros Ferreira ${ }^{4}$
}

\begin{abstract}
RESUMO O Sistema de Planejamento do Sistema Único de Saúde (PlanejaSUS) estabeleceu instrumentos básicos, que têm por finalidade apoiar a gestão da saúde, porém necessitam de informações confiáveis para a sua construção. Para isso, a gestão da informação é imprescindível, pois possibilita o desenvolvimento de ações oportunas e resolutivas. Este estudo teve como objetivo descrever e analisar a percepção de gestores e técnicos do setor saúde sobre a gestão da informação para o planejamento regional do SUS. Trata-se de uma pesquisa descritiva com abordagem qualitativa, na qual foram entrevistados 26 participantes, entre gestores e técnicos dos municípios e do estado, que compõem o Departamento Regional Saúde XIII - Ribeirão Preto/SP.

\footnotetext{
1 Fisioterapeuta graduada pela Universidade de São Paulo - USP. Mestre e doutoranda pelo Departamento de Medicina Social - FMRP - USP Ribeirão Preto. Membro do Centro Brasileiro de Estudos de Saúde - CEBES Núcleo Ribeirão Preto

2 Mestranda pelo Departamento de Medicina Social da Faculdade de Medicina de Ribeirão Preto da Universidade de São Paulo - Ribeirão Preto/São Paulo/Brasil

3 Docente aposentado pelo Departamento de Medicina Social da Faculdade de Medicina de Ribeirão Preto da Universidade de São Paulo - Ribeirão Preto/São Paulo/Brasil

4 Docente pelo Departamento de Medicina Social da Faculdade de Medicina de Ribeirão Preto da Universidade de São Paulo - Ribeirão Preto/São Paulo/Brasil
} 
Para análise dos dados, foi utilizada a vertente temática da Análise de Conteúdo. Certas limitações foram encontradas para o uso de informações, relacionadas à alimentação, ao uso dos sistemas e à falta de compartilhamento de dados entre os responsáveis pelo planejamento. No entanto, o próprio processo de construção dos instrumentos de planejamento proporcionou o desenvolvimento de um olhar crítico sob a realidade locorregional. Concluiu-se que os participantes reconheceram a importância da gestão da informação e de seus atributos, porém relataram inconsistências dos dados disponíveis. Nesse sentido, o PlanejaSUS pretendeu ser um sistema de informação para auxiliar na formalização da coleta, organização e disseminação da informação, colaborando com o melhor reconhecimento da realidade dos municípios, apesar das dificuldades para o seu uso no cotidiano da gestão.

Palavras-chave: Gestão da Informação; Planejamento em Saúde; Regionalização, Sistema Único de Saúde; Sistemas de Informação.

\begin{abstract}
The System Planning of the Unified Health System (PLANEJASUS) has established basic instruments that aim the support health management, but require reliable information for its construction. For this, the management of the information becomes essential, because it allows the development of timely and resolutive actions. This study aimed to describe and analyze the perception of managers and technicians of the health sector on the information management for SUS regional planning. This is a descriptive research with a qualitative approach, in which 26 participants were interviewed, among managers and technicians from the municipalities and the state that comprise the Regional Health Department XIII - Ribeirão Preto/SP. For the analysis of the data, the thematic aspect of the Content Analysis used. There were certain limitations to the use of information, related to food, the use of information systems and the lack of sharing of data among planners. However, the very process of constructing planning instruments has provided the development of a critical look at the locoregional reality. It concluded that the participants recognized the importance of information management and its attributes, but reported inconsistencies in the available data. In this sense, PlanejaSUS intended to be an information system to help formalize the collection, organization, and dissemination of information, collaborating with the better recognition of the reality of the municipalities, despite the difficulties for its use in the daily management.
\end{abstract}

Keywords: Information Management, Health Planning; Regional Health Planning; Unified Health System; Information Systems

RESUMEN: El Sistema de Planificación del Sistema Único de Salud (PlanejaSUS) estableció los Tempus, actas de saúde colet, Brasília, 11(4), 123-145, dez, 2017. Epub Ago/2018 ISSN 1982-8829 
instrumentos básicos de planificación, que tienen por finalidad apoyar la gestión de la salud, pero necesitan informaciones confiables para su construcción. Para ello, la gestión de la información se vuelve imprescindible, pues posibilita el desarrollo de acciones oportunas y resolutivas. Este estudio tuvo como objetivo describir y analizar la percepción de gestores y técnicos del sector salud sobre la gestión de la información para la planificación regional del SUS. Se trata de una investigación descriptiva con enfoque cualitativo, en la cual fueron entrevistados 26 participantes, entre gestores y técnicos de los municipios y del estado que componen el Departamento Regional Salud XIII - Ribeirão Preto/SP. Para el análisis de los datos, se utilizó la vertiente temática del Análisis de Contenido. Se han encontrado ciertas limitaciones para el uso de informaciones, relacionadas con la alimentación, el uso de los sistemas de información y la falta de intercambio de datos entre los responsables de la planificación. Sin embargo, el propio proceso de construcción de los instrumentos de planificación proporcionó el desarrollo de una mirada crítica bajo la realidad locorregional. Se concluye que los participantes reconocieron la importancia de la gestión de la información y de sus atributos, pero relataron inconsistencias de los datos disponibles. En este sentido, el PlanjaSUS pretendió ser un sistema de información para auxiliar en la formalización de la colecta, organización y diseminación de la información, colaborando con el mejor reconocimiento de la realidad de los municipios, a pesar de las dificultades para su uso en el cotidiano de la gestión.

Palabras claves: Gestión de la Información; Planificación en Salud; Regionalización; Sistema Único de Salud; Sistemas de Información

\section{INTRODUÇÃO}

A proposta de planejamento em saúde contida na organização do Sistema Único de Saúde (SUS) tem nas orientações normativas da Constituição Federal de $1988^{1}$ e nas Leis Orgânicas da Saúde (LOS) no 8080/90² e nº 8142/90, principalmente, a operacionalização do princípio da descentralização dos processos decisórios, incluindo a regionalização e a hierarquização da rede de saúde como proposta para estruturação das ações e dos serviços. Entre outras normas que trouxeram instrumentos para o desenvolvimento do planejamento de maneira sistematizada ${ }^{4,5}$, o Pacto pela Saúde ${ }^{6}$ teve a finalidade de complementar a legislação vigente ${ }^{7}$. Esse Pacto envolveu três componentes, o Pacto pela Vida, o Pacto em Defesa do SUS e o Pacto pela Gestão. Esse último, especificamente, radicalizou a descentralização por meio da desburocratização dos procedimentos normativos, da instituição dos Colegiados Gestores Regionais (CGR), hoje denominados Comissão Intergestora Regional (CIR) ${ }^{8}$ e da definição de responsabilidades sanitárias de cada instância gestora, superando a lógica anterior de habilitação. Dessa forma, aumentou o potencial de fortalecimento da gestão compartilhada, dialogada e solidária no SUS.

ISSN 1982-8829 Tempus, actas de saúde colet, Brasília, 11(4), 123-145, dez, 2017. Epub Ago/2018 
Além disso, o Pacto pela Gestão formalizou as ferramentas de planejamento da regionalização e, também trouxe em seu escopo o Sistema de Planejamento do SUS (PlanejaSUS), que estabeleceu os instrumentos básicos do planejamento - Plano de Saúde (PS), Programação Anual de Saúde (PAS) e Relatório Anual de Gestão (RAG) ${ }^{9}$. Em síntese, esses instrumentos têm por finalidade apoiar o gestor municipal na condução do SUS, de modo a alcançar a efetividade das ações e o aperfeiçoamento do sistema, bem como servir de base para a estruturação do planejamento regional. Entretanto, para que essa condução ocorra de maneira adequada e resolutiva, a construção desses instrumentos deve se apoiar em informações, sendo essas entendidas enquanto um recurso, assim como os recursos humanos, tecnológicos e financeiros ${ }^{10}$.

O conceito de informação passou por algumas transições ao longo das últimas décadas, sendo descrita inicialmente como um requisito burocrático na década de 1950, cuja importância organizacional estava atrelada à diminuição de custos. A partir dos anos 90, a definição de informação passou a ser ligada à vantagem competitiva, sendo importante para garantir a prosperidade e a sobrevivência ${ }^{11}$. No campo da ciência da informação, seu conceito está ligado ao "conhecimento comunicado", onde estão embutidas considerações sobre novidade e relevância, ao se referir à produção de conhecimento, por meio de sua seleção e interpretação da informação a partir de certo contexto $^{12}$. Por fim, a informação também pode ser entendida enquanto uma representação do real, ou seja, uma reprodução de fatos a partir de certo referencial teórico ou visão de mundo ${ }^{13,14}$.

Nesse sentido, a informação em saúde se torna uma ferramenta importante para a tomada de decisão, permitindo o atendimento das demandas/necessidades em saúde, de acordo com o perfil da população. Para isso, a gestão dessa informação é imprescindível, pois possibilita o desenvolvimento oportuno das ações, por meio da combinação de aspectos tecnológicos e estratégicos que permitam seu uso na produção e organização do conhecimento ${ }^{15}$.

Desta forma, a gestão da informação incorpora o planejamento, a organização e o seu controle, sendo uma etapa anterior ao processo de tomada de decisão ${ }^{16}$. Ademais, para que sua utilização ocorra oportunamente e de maneira satisfatória, necessita-se que sejam estabelecidos parâmetros referentes à relevância das informações, à qualidade dos dados e ao fluxo de sua alimentação e acesso. Posteriormente, a gestão da informação implica em organizá-la e armazená-la, para que seja facilmente localizada e recuperada para uso quando necessário ${ }^{17}$. Essa gestão possibilita que a tomada de decisões seja feita de maneira estratégica e oportuna.

No setor público, especificamente, a gestão da informação assume amplas dimensões, tendo como objetivos principais a prestação de contas e a transparência, uma vez que pode ser utilizada para justificar as decisões tomadas mediante informações geradas de maneira confiável. Em contrapartida, a gestão inadequada das informações pode gerar diversos problemas, como a ineficiência do sistema ou mesmo questões relacionadas à legalidade do processo decisório. Além 
disso, a gestão da informação deve ser desenhada para atender às necessidades institucionais e estar embasada em políticas públicas, que forneçam base legal para a exigência das informações coletadas, bem como sua forma e periodicidade ${ }^{18}$.

Nesse sentido, a gestão da informação incorporada ao processo de planejamento em saúde tem potencialidade para trazer maior agilidade, eficiência e efetividade para a gestão do SUS, possibilitando o cumprimento de seu arcabouço legal, assim como o conhecimento da realidade epidemiológica, demográfica, sanitária e orçamentária ${ }^{19}$, necessário para a resolução de problemas e para a avaliação das decisões tomadas. Para tanto, a gestão da informação tem um papel político estratégico, pois cria condições de interlocução entre setores, unidades e pessoas, necessário para o alcance de objetivos comuns ${ }^{20}$ que levam em consideração, em geral, interesses institucionais ${ }^{21}$.

Considera-se que para o planejamento do SUS ser efetivo é necessário existir compartilhamento de informações entre os diferentes atores sociais ${ }^{22,23,24,25}$ tanto na construção de seus instrumentos quanto no acompanhamento de sua execução. Em contraposição ao preconizado, notam-se fragilidades no uso de informações no gerenciamento do SUS, bem como uma grande carência no âmbito de sua gestão para o atendimento das demandas assistenciais e de gerenciamento ${ }^{14,26}$.

Tendo em vista que a produção científica relacionada à gestão da informação ainda é escassa, no contexto da CIR (instância de planejamento regional) ${ }^{27,28}$. Este estudo teve como objetivo descrever e analisar a percepção de gestores e técnicos do setor saúde sobre a gestão da informação para o planejamento regional do SUS.

\section{METODOLOGIA}

Trata-se de um estudo descritivo com abordagem qualitativa, desenvolvido no território do Departamento Regional de Saúde (DRS) XIII, órgão da Secretaria de Estado da Saúde de São Paulo (SES SP), com uma população estimada de 1.327.989 habitantes $^{29}$. Este DRS é conformado por 26 municípios, agrupados em três Regiões de Saúde (Aquífero Guarani, Horizonte Verde e Vale das Cachoeiras) e suas respectivas CIR, tendo o município de Ribeirão Preto como sede administrativa e polo assistencial regional. Pontua-se que o projeto de pesquisa foi apresentado para representantes de todos os municípios, no DRS XIII, durante as reuniões das CIR das três Regiões de Saúde (RS).

No desenvolvimento da pesquisa os municípios foram agrupados dentro de suas respectivas RS, segundo a classificação do PlanejaSUS ${ }^{9}$ : Grupo A - até 10 mil habitantes; Grupo B - mais de 10 mil até 50 mil habitantes e Grupo C - Mais de 50 mil habitantes. Após a classificação, foi sorteado dentro de cada RS um município de cada Grupo. Nos casos onde havia somente um município dentro do Grupo, o mesmo foi incluído na pesquisa, sem a realização do sorteio. O Quadro 1 
apresenta os municípios classificados por porte populacional em cada RS.

Quadro 1 - Distribuição dos municípios segundo grupo populacional e Regiões de Saúde do DRS XIII - Ribeirão Preto-SP

\begin{tabular}{|c|c|c|c|}
\hline Grupo Populacional & $\begin{array}{c}\text { Municípios } \\
\text { Aquífero Guarani }\end{array}$ & $\begin{array}{c}\text { Municípios } \\
\text { Horizonte Verde }\end{array}$ & $\begin{array}{c}\text { Municípios } \\
\text { Vale das Cachoeiras }\end{array}$ \\
\hline \multirow{3}{*}{ Grupo A } & Guatapará & \multirow{3}{*}{ Dumont } & Santa Cruz da Esperança \\
\hline & & & Cássia dos Coqueiros \\
\hline & & & Santo Antônio da Alegria \\
\hline \multirow{7}{*}{ Grupo B } & Luís Antônio & Pradópolis & \multirow{3}{*}{ Altinópolis } \\
\hline & São Simão & Barrinha & \\
\hline & Santa Rosa do Viterbo & Pitangueiras & \\
\hline & $\begin{array}{c}\text { Santa Rita do Passa } \\
\text { Ouatro }\end{array}$ & Guariba & \multirow{2}{*}{ Brodósqui } \\
\hline & Cravinhos & Pontal & \\
\hline & \multirow[b]{2}{*}{ Serrana } & Monte Alto & \multirow[t]{2}{*}{ Cajuru } \\
\hline & & & \\
\hline & & Jaboticabal & \multirow[b]{2}{*}{ Batatais } \\
\hline Grupo C & Ribeirão Preto & Sertãozinho & \\
\hline
\end{tabular}

Fonte: Elaborado pelos autores, com base nos dados do DATASUS/IBGE ${ }^{29}$.

Desta forma foram selecionados três municípios de cada RS, um de cada porte populacional, totalizando 9 municípios. O critério de inclusão dos participantes no estudo considerou o exercício da função de secretário da saúde (gestor) e de técnico de saúde do setor de planejamento. Posteriormente foram identificados os participantes em cada município selecionado e realizado o convite, por contato telefônico, para participação na pesquisa. Partindo-se do recorte empírico foram convidados dois técnicos do setor de planejamento e o gestor de cada um dos nove municípios e também dois técnicos e o gestor do DRS XIII, totalizando 30 participantes. Destes, quatro indivíduos não retornaram as ligações ou desistiram de participar da pesquisa, assim o estudo contou com 26 participantes, de acordo com a distribuição apresentada no Quadro 2.

Quadro 2 - Participantes selecionados para compor o estudo

\begin{tabular}{llcr}
\hline \multicolumn{1}{c}{ Participantes } & \multicolumn{1}{c}{ Origem } & Função & N $^{0}$ \\
\hline Estadual & Departamento Regional de Saúde XIII - & Gestor & 1 \\
& Ribeirão Preto/SP & Técnicos & 2 \\
Municipal & Serra Azul (Grupo A) & Gestor & 1 \\
(Região de Saúde & Cravinhos (Grupo B) & Testor & 1 \\
Aquífero Guarani) & Géstor & 1 \\
& Ribeirão Preto (Grupo C) & Técnicos & 2
\end{tabular}




\begin{tabular}{llll} 
& Dumont (Grupo A.) & Gestor & 1 \\
$\begin{array}{l}\text { Municipal } \\
\text { (Região de Saúde }\end{array}$ & Técnicos & 2 \\
Horizonte Verde) & Gestor & 1 \\
& Jaboticabal (Grupo C) & Técnicos & 2 \\
Géstor & Técnicos & 2 \\
Municipal & Santa Cruz da Esperança (Grupo A) & Gestor & 1 \\
Tegião de Saúde & Gecnicos & 1 \\
Vale das Cachoeiras) & Altinópolis (Grupo B) & Gestor & 2 \\
& Batatais (Grupo C) & Técnicos & 1 \\
\hline
\end{tabular}

Fonte: Elaborado pelos autores.

Os participantes responderam à entrevista realizada por profissional com experiência em coleta de dados qualitativos e previamente treinado para a utilização do roteiro, composto por 16 perguntas, as quais foram distribuídas em quatro blocos, sendo eles: processo de planejamento no município e na CIR; gestão da informação; instrumentos de planejamento e; Sistema de Planejamento do SUS (PlanejaSUS). Entre as perguntas realizadas, destacam-se: "Considerando que a informação é fundamental para desenvolver o planejamento em saúde fale um pouco sobre a gestão da informação (produção, organização, recuperação, acesso e uso) em seu município e na CIR.”; "Em sua opinião a atual situação da gestão da informação, em seu município e na RS, favorece ou dificulta o processo de planejamento local e na CIR? Por quê?".

As entrevistas foram realizadas durante o ano de 2010, nas Secretarias Municipais da Saúde dos municípios sorteados e no DRS XIII, no caso do ente estadual. Todas as entrevistas foram áudiogravadas e transcritas posteriormente, sendo a duração média de cada entrevista de 40 minutos.

A análise dos dados foi realizada por meio da técnica de Análise de Conteúdo (vertente temática) ${ }^{30}$, sendo o tema utilizado como unidade de registro. As categorias foram inicialmente construídas empiricamente e passaram por modificações ao longo da análise, dentro de um processo dinâmico e constante de construção entre a prática e a teoria. Ao final, chegou-se a um grande tema, formado por quatro núcleos de sentido.

Este estudo contemplou as recomendações da Comissão Nacional de Ética em Pesquisa CONEP e foi aprovado pelo Comitê de Ética em Pesquisa do Centro de Saúde Escola da Faculdade de Medicina de Ribeirão Preto-USP (protocolo n ${ }^{\circ}$ 342/CEP/CSE-FMRP-USP). A fim de garantir o anonimato dos participantes, utilizou-se de numerais arábicos, de acordo com a ordem de coleta dos dados, ou seja, Entrevistado 1 (E1), Entrevistado 2 (E2), e assim sucessivamente. Este estudo contou com o financiamento da Fundação de Amparo à Pesquisa do Estado de São Paulo (FAPESP) (Processo: 2010.1.30353.01.9).

\section{RESULTADOS}

Dentre as pessoas entrevistadas, o tempo médio na instituição vinculada ao município foi de 11,5 anos (variando de 0,66 a 24 anos), sendo o tempo médio na atual função de 5,1 anos (variando 
de 0,66 a 22 anos). Nota-se que a maior parte dos participantes $(n=20)$ tinha formação de nível superior (GRÁFICO 1).

\section{Gráfico 1 - Distribuição dos participantes por profissão}

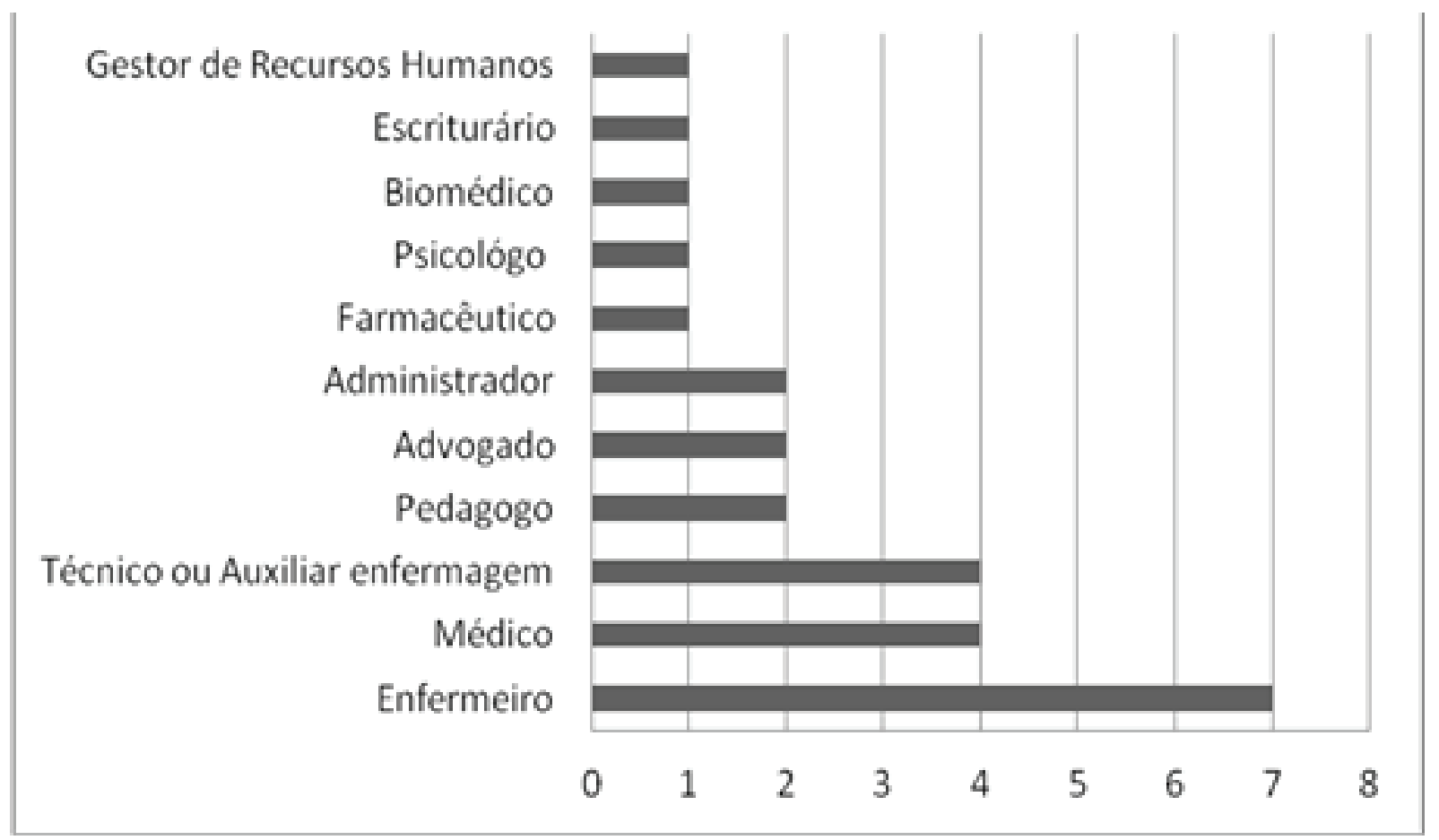

Fonte: Dados da pesquisa.

Em relação à análise das respostas, foi formado o grande tema "A gestão da informação no processo de planejamento regional do SUS", sendo seus núcleos de sentido apresentados a seguir.

\section{Fonte de dados e sistemas de informação: a produção da informação para o planejamento}

Tendo em vista as inúmeras fontes de dados e sistemas de informação (SIS) do SUS mencionados pelos entrevistados, os SIS foram classificados em: "Sistema de Informação Municipal", de uso restrito às unidades de saúde e Secretarias Municipais de Saúde (SMS), como é o caso do sistema Hygia em Ribeirão Preto; "Sistema de Informação Supramunicipal", vinculados ao Ministério da Saúde (MS) e à Secretaria Estadual de Saúde (SES), como o Sistema de Informação sobre Mortalidade e o Sistema de Informação de Nascidos Vivos, e, especificamente, o PlanejaSUS.

Quanto ao 'Sistema de Informação Municipal' houve relatos referentes à dificuldade com a sua alimentação e divergência entre os dados. Apesar disso, os responsáveis pelo planejamento relataram que a informatização dos municípios trouxe grande avanço para o acesso à informação, em tempo pertinente para embasar o planejamento das ações.

\footnotetext{
“A questão da informação é o grande desafio (...) dentro às vezes do mesmo setor ou da secretaria há diversidade de dados. (...) tem que se investir muito na questão das pessoas informarem corretamente, alimentar corretamente os bancos de dados". (E6)
} 
"A partir do momento em que você tem em mãos os dados do seu município, você abre ali um leque de opções para você atuar, nas ações preventivas, curativas, seja o que for". (E23)

Os relatos acerca do 'Sistema de Informação Supramunicipal' foram de preocupação com o cumprimento de prazos para sua alimentação, sendo essa exigência reforçada por parte da esfera estadual. Os participantes vincularam essa alimentação, principalmente, ao financiamento e repasse de verbas, enfatizando a necessidade de construção das séries históricas, e não ao uso de informações para o planejamento de futuras ações ou avaliação dos serviços prestados.

"Você tem sistema que você tem que alimentar semanalmente, mensal, quinzenal, então o DRS cobra essa alimentação, né, no dia do prazo fica mandando e-mail, lembrando todos, então a gente é obrigado a fazer." (E23)

“A maior limitação nossa vem na alimentação da informação (...) dois anos atrás eu tinha um pronto atendimento que não tinha produção, que não tem série histórica, então para o Ministério da Saúde isso veio de fato contribuir para que a gente tivesse déficit no teto financeiro". (E20)

A dificuldade de alimentação dos SIS e a inconsistência de suas informações foram apontadas nas falas como elementos dificultadores para o embasamento do planejamento regional. Essas inquietações foram assinaladas tanto pelos atores dos municípios quanto do DRS, devido ao impacto no diagnóstico em saúde e, consequentemente, no financiamento e na pactuação de ações/ serviços, uma vez que a análise da realidade dos sistemas de saúde ficava prejudicada.

\footnotetext{
“Eu acho que um diagnóstico bem feito é a base para todo planejamento. Infelizmente às vezes a gente trabalha com dados irreais, mas pelo menos a gente tem alguma coisa para trabalhar". (E24)

“Até pouco tempo atrás a gente pegava o mapa de determinado município, se checava determinado procedimento eram dez no mês, dez, dez, dez, dez, então isso não era real. E essa dificuldade ainda permanece um pouco, na PPI muitos municípios tiveram problemas porque não registravam a produção, e o que vale é o que está no banco de dados". (E24)
}

Atribuiu-se ao fator humano a dificuldade de alimentação dos SIS, comprometendo a qualidade dos dados gerados. Uma sugestão dos participantes do estudo foi dar maior transparência aos relatórios dos SIS, apresentando-os, por exemplo, em audiências públicas, no sentido de compromissar os profissionais com a gestão da informação.

“O SISPRENATAL ficava muito a cargo do enfermeiro da unidade e aí ele esquecia de informar que aquela paciente já tinha fechado, porque tem a consulta puerperal para você fechar e o município receber." (E13)

Além disso, devido à sobrecarga do trabalho e a necessidade de buscar dados em diferentes sítios, que despende certo tempo, emergiu nas falas a demanda de criação de um sistema unificado 
e específico para o planejamento em saúde, capaz de recuperar informações disponíveis em outros SIS do SUS, permitindo a construção de parâmetros e indicadores regionais.

\footnotetext{
“A gente tem vários sistemas de informação que a gente usa, né, só que muitos não conversam entre si esses sistemas, os dados não são cruzados, e isso acaba complicando, então você tem a mesma informação de um jeito em um local de outro". (E26)

“[...] Pra ser mais ágil a gente precisa condensar muito mais do que ter que olhar um sistema, busco o outro, traz um outro sistema, eu acho que a gente precisava de um sistema meio que único de planejamento". (E25)
}

Quanto ao PlanejaSUS apenas cinco respondentes ligados aos municípios demonstraram conhecimento sobre o assunto. Dos três participantes ligados ao DRS, apenas um expressou sua opinião sobre o PlanejaSUS, os outros dois não souberam falar sobre o tema. As falas que exprimiram opinião sobre o PlanejaSUS trouxeram a importância do sistema para a construção das ferramentas de planejamento, desde que o sistema seja alimentado e utilizado da maneira correta.

\footnotetext{
"Para poder fazer as coisas acontecerem de fato, tem que analisar, tem que planejar e depois por em ação e avaliar, então eu acho que o PLANEJASUS é fundamental para nortear as ações em saúde". (E2)

"É que como todo programa, né, o que ta por trás, na alimentação dele, então... o positivo e negativo ta ali junto. O programa é bom, mas e o que está por trás, para alimentar, para desenvolver, para... voltar na mesma coisa sempre". (E5)
}

Dentre os profissionais e gestores municipais que emitiram alguma opinião sobre o PlanejaSUS, seis o apontaram como um sistema que auxiliou na ordenação e construção das ferramentas de planejamento em saúde. No entanto, foram apontadas dificuldades no uso desse sistema, relativas à sua implantação e à aplicação de sua proposta no cotidiano da gestão.

“O PlanejaSUS, ele dá uma orientação importante pra a gente e acho que... é uma forma de padronizar, eu acho que o caminho é esse, só precisa ser mais prático pra gente, na hora de elaborar é que tem a dificuldade um pouco, mas isso já facilitou bastante".(E12)

“Acaba tendo tanta informação que fica longe da prática, que apesar de ser fácil, mas depende ainda da postura ativa da pessoa querer procurar, sabe, não é muita coisa oficializada assim que tenha que usar na prática, eu acho que essa distância da prática que atrapalha”. (E2)

\section{Construção das Ferramentas de Planejamento: organização das informações no planejamento}

A experiência de construção das ferramentas de planejamento refinou a crítica dos participantes da pesquisa relacionada ao processo de planejamento locorregional, uma vez que os gestores e 
técnicos conseguiram olhar para as suas realidades de maneira mais ampla.

"Os instrumentos ajudam a gente a ter essa visão que a gente não consegue ter no dia a dia porque você corre muito, tem muita... então quando você para e olha para ele, você tem outra visão que não é a visão do dia a dia". (E13)

Outros relatos apontaram uma apreciação positiva da vivência de elaboração dos instrumentos com relação à possibilidade de direcionamento das ações/serviços de saúde para as realidades municipais e aproximação das ferramentas de planejamento à situação orçamentária locorregional, desvinculando um pouco a pressão das políticas indutoras das escolhas dos gestores e dos profissionais da área técnica do planejamento em saúde. Para os entrevistados, além de norteadoras das ações e das decisões, as ferramentas de planejamento também podem ser orientadoras do próprio orçamento, quando construídas previamente à elaboração do Plano Plurianual (PPA) e da Lei de Diretriz Orçamentária (LDO).

"Sem esses instrumentos de planejamento a gente não tem diretriz, sem diretriz a gente fica sem saber aonde quer chegar, então... não é uma coisa aleatória (...) Não é porque o governo federal abre uma linha de financiamento, como foi aberta a pouco tempo, do PAC2, que a gente vai sair por aí pedindo 15 unidades de saúde". (E7)

As falas que apontaram para o planejamento regional trouxeram que essas ferramentas seriam meios para a organização dos serviços de saúde da região e para a pactuação da Programação Pactuada e Integrada (PPI).

“A gente já começou a trabalhar, o que nunca tinha acontecido, estamos já trabalhando, sentando e já começando a construir a nossa programação anual de 2012. Por quê? Porque o que acaba acontecendo, quando eles vão fazer... não casa muito... quando eles vão fazer o orçamento a gente ainda não fez a programação e aí não casa. Então nós vamos nos adiantar, fazer nossa programação para que nos próximos orçamentos eles acompanhem a nossa programação”. (E13)

"Eu acho que tem que ter planejamento até pra que haja um reconhecimento do meu cenário (...) para que eu possa aparar as arestas que existem dentro do meu sistema de saúde local e regional que existem e, portanto, não há dúvida que o planejamento vai ser a base, né, para que se discuta PPI, para que se discuta PAC, para que se discuta crescimento municipal, crescimento regional, para que se brigue por recursos, para que se brigue por aumento de financiamento, de novos equipamentos, toda a estruturação da rede de saúde de média e alta complexidade, a atenção básica, média e alta complexidade”. (E20)

\section{Revisitando as Ferramentas de Planejamento: uso das informações na rotina da gestão e avaliação das ações propostas}

Alguns participantes que reportaram o uso das informações organizadas nas ferramentas de planejamento, como norteadoras das ações dos gestores e técnicos, mencionaram tentativas de 
consulta às metas e objetivos planejados continuamente, visando a inserção desses instrumentos na prática da gestão. Com relação à avaliação das ações programadas, as falas apontaram no sentido de avaliar o cumprimento das metas pactuadas para poder repensar os próximos PMS e PAS. Alguns relatos citaram a avaliação de maneira continuada, outros apenas ao final da gestão, para tentar cumprir o que havia sido planejado no mesmo ano ou no seguinte, respectivamente.

\footnotetext{
"A gente tem tentado fazer um trabalho para que as pessoas utilizem esses instrumentos como uma ferramenta de trabalho no dia a dia. Então eu vejo que de alguns anos para cá está bastante evoluído, a gente está tentando com que as pessoas não vejam apenas como um papel burocrático, mas que isso é importante no processo de gestão". (E8)

"Vemos em cima do relatório de gestão o que está defasado, o que não conseguimos atingir, a meta que não conseguimos atingir para a gente propor no próximo plano". (E14)
}

A pressão midiática influenciando a condução das ações programadas foi apontada como um obstáculo à execução do planejamento. Assim, para suprir um acontecimento inesperado, ou supervalorizado pela mídia, existe, muitas vezes, a necessidade de reprogramar as ações para que não seja ultrapassado o orçamento aprovado naquele determinado período.

"Eles (instrumentos de planejamento) são importantes porque o dia a dia faz com que você só apague incêndios (...) na cidade uma característica, acredito que das outras também, muito forte, que é a questão política e a questão da imprensa, né? Então eles fazem as notícias só com as coisas ruins e dão soluções ou exigem questões que não são importantes... é um ponto... um fato pontual vira um cavalo de Troia. Então se não houver a base muito sólida, inclusive para discutir com a sociedade o que é que está acontecendo você se perde". (E8)

Outras dificuldades relatadas foram relacionadas ao uso das ferramentas de planejamento para a gestão em saúde de uma maneira global, por isso, alguns gestores fragmentam o olhar em linhas de cuidado, visão essa que também permeia as políticas de saúde e programas do MS.

“Eu tenho procurado trabalhar por linhas de cuidado mesmo... saúde da mulher, saúde do idoso... atenção básica... porque aí você consegue visualizar... porque se você for trabalhar saúde ampla, você só fica apagando incêndio". (E13)

A prática gestora integrada entre as esferas municipais e estadual também surgiu como outro ponto deficitário, reforçando a fragmentação do planejamento locorregional, como se pôde notar na fala dos entrevistados. Tais falas deixaram em aberto o emprego do PS dos municípios para concretizar as ações planejadas e o uso das ferramentas de planejamento pelo ente estadual, em seu dia a dia. 
“É inviável ler todos os planos no colegiado, então eles foram aprovado "pró-forma”, (...) ia ficar uma coisa muito maçante a gente ficar lendo plano por plano. Então um gestor confia no outro, o que foi proposto é aprovado (...) o tempo que vai se perder, é burocrático, e a gente tem prazo para encaminhar a lista para a CIB (Comissão Intergestores Bipartite)". (E24)

"No dia a dia às vezes chega um pedido... (...) algum pedido de recurso, alguma coisa... a gente olha o plano, olha o relatório, se está prevista alguma coisa em relação aquilo, se tem algum dado referente ao equipamento que está sendo solicitado à unidade, a abrangência populacional, então a gente utiliza nesse sentido". (E24)

\section{Comunicação institucional: a transmissão e a solicitação de informações}

Notou-se, pelas falas de alguns participantes, que não havia repasse de informações entre os técnicos que se deslocavam para participar das reuniões no DRS e àqueles que ficavam nos municípios, mesmo sendo esses representantes da gestão e responsáveis pelo planejamento.

"Do colegiado eu posso falar pouco porque eu quase não participo, a minha atuação é mais aqui dentro (...) cada um que tá ali [no CGR] tá representando o seu município, com as suas dificuldades e sua facilidade, de uma forma condensada". (E5)

"Já fui na reunião... mas é uma vez ou outra... não tenho uma frequência não, é muito raramente... muito raro, não sei falar como está o processo de planejamento lá”. (E9)

No caso da falta de repasse das informações, ocorre o acúmulo de informações pelo secretário ou técnico que se traduz em não transmissão para os respectivos municípios, ou mesmo pela sua falta de registro sistematizado, que facilite seu armazenamento e posterior acesso e compartilhamento pelas equipes municipais. Esse tipo de comportamento apareceu como um fator importante na sensação de descontinuidade administrativa a cada mudança de gestão, trazida como preocupação nas falas dos participantes, uma vez que a informação fica centralizada em um único indivíduo que pode ser substituído conforme a troca de prefeito.

“A gestão anterior ficou muito confusa porque perdeu muitos dados, foi uma gestão conturbada no município na saúde, então a gente tinha que cavar muitas informações, buscar muitas informações, pra apontar mesmo as dificuldades para poder por no plano, uma ação ali planejada para gente cumprir, uma meta". (E23)

Com relação à postura do DRS, referente à comunicação com os participantes das reuniões da CIR, observou-se existir uma divisão de opiniões entre os gestores e técnicos municipais. Quem elogiou a comunicação disse que a equipe de planejamento estadual usava de diferentes canais de comunicação para que a informação chegasse até o município. Quem a criticou argumentou que a comunicação acontecia de maneira lenta, colocando o município em situações de risco para perda dos prazos estipulados pelos entes supramunicipais.

ISSN 1982-8829 Tempus, actas de saúde colet, Brasília, 11(4), 123-145, dez, 2017. Epub Ago/2018 
“Ótimo acesso, eles mandam e-mail a gente recebe (...) você não pega se você não quiser, se não bastasse eles ligam pra saber se você recebeu, ligam em celular, quer dizer, a comunicação hoje é muito boa, o pessoal se esforça muito, no colegiado também, todos têm telefone de todos, todos os profissionais têm o telefone um do outro, eles mandam tudo... esses dias eles mandaram um e-mail com todos os telefones e e-mails dos outros gestores". (E21)

"Muitas vezes a gente tem que buscar a informação no Cosems, em outro órgão, porque muitas vezes a hora que chega um projeto lá, o projeto é para aquele dia, para aquele momento, senão você perde o projeto. Então eu acho que muitas vezes essa informação às vezes ou ficou parada, ou teve uma certa dificuldade pra ta passando, então eu sinto isso. Então se a gente não buscar em outro nível, a gente perde muita coisa. Então essa informação de projeto eu acho que deveria ser mais divulgada no DRS". (E10)

Problemas de comunicação foram citados também pelo ente estadual, quando os participantes relataram dificuldades quanto ao retorno dos municípios aos comunicados e solicitações do DRS.

"A principal dificuldade ainda é a informação. A gente tem a questão daqui, a questão de e-mails, às vezes a gente não consegue, a gente transmite, o profissional no município até abre o e-mail, olha, mas não dá sequência; então a informação a gente tem que garantir muito e mesmo aqui no DRS às vezes a gente não recebe, às vezes a gente não sabe quem mandou, então eu acho que o nosso maior nó aí é esse". (E26)

\section{DISCUSSÃO}

As informações em saúde são consideradas como um dos substratos do processo de planejamento e de tomada de decisão no sistema de serviços de saúde. A partir deste reconhecimento, de acordo com Bispo Junior e Gesteira ${ }^{31}$.

\footnotetext{
"A informação não pode ser considerada apenas como recurso secundário. Essa deve ser priorizada, devendo, pois, existir uma política de gerenciamento de informação, que objetive planejar e coordenar os mecanismos de seleção, identificação, coleta aquisição, registro, classificação, armazenamento, processamento, recuperação, análise, apresentação e difusão das informações relacionadas à saúde" ${ }^{31}$.
}

As informações e, principalmente, a sua gestão, conferem uma base ao processo decisório por fornecerem subsídios às alternativas para solução dos problemas e aos resultados decorrentes das decisões. Essas, por sua vez, são executadas a partir de condições variadas e tendem a oferecer um menor risco e maior assertividade quando ocorrem de maneira planejada e com base em informações reais.

Nesse sentido, a produção da informação é uma etapa essencial, que deve levar em consideração os meios como são produzidas e os espaços em que são armazenadas. O consumo dos dados/ 
informações faz parte da etapa de análise situacional do planejamento, que consiste na identificação, formulação e priorização de problemas em saúde ${ }^{32}$. Sendo assim, as fontes que subsidiam esse processo são importantes para embasar, de maneira consistente, a análise da situação de saúde, no sentido de que a orientação das medidas a serem adotadas seja consistente e resolutiva ${ }^{32}$.

Pode-se notar no estudo que as fontes mais consultadas pelos entrevistados foram os SIS, tanto de abrangência municipal, quando ligados a órgãos supramunicipais. Esse tipo de dado advém da informatização do setor saúde, que desde sua gênese deve seguir uma lógica organizativa relacionada ao processo de saúde/doença/cuidado, que adquire relevância social e política em determinado contexto histórico. Dada essa importância, justifica-se o seu monitoramento por meio de dispositivos do Estado ${ }^{21}$.

Contrapondo-se a essa relevância da vigilância sob essas informações, a dificuldade no uso do conteúdo informacional dos SIS foi relacionada à sua inconsistência que, por sua vez, pode estar vinculada à falta de formalização dos processos de coleta e à organização da informação, bem como a ausência de padronização dos conteúdos disponibilizados e utilizados pelas instituições de saúde $^{33}$. Nesse processo, o fator humano tem grande influência e deve ser levado em consideração durante a criação, a implantação e a reengenharia dos sistemas informatizados ${ }^{33}$. Entretanto, devese lembrar de que a qualidade da informação influencia diretamente o potencial de resposta às demandas e necessidades do setor saúde ${ }^{20}$. Para serem úteis aos processos decisórios da gestão, as informações devem possuir alguns atributos, entre eles: estar adequada às necessidades do gestor (adequação às necessidades), ser gerada em tempo adequado para sua utilização (oportunidade), possibilitar que os dados sejam agregados ou reorganizados (agregabilidade) e serem fidedignas (confiabilidade), pois informações distorcidas podem ser mais prejudiciais que a falta das mesmas ${ }^{34}$.

Tendo em vista estes atributos da informação, nota-se nas falas dos participantes que os SIS municipais tendem a falhar em relação a confiabilidade. Por sua vez, os SIS supramunicipais tendem a ter falhas em relação ao atributo relacionado à oportunidade, pois os respondentes apontaram dificuldades de acesso aos dados neles contidos. Esses relatos corroboram os achados de Moraes ${ }^{13}$ e Vidor $^{35}$, que apontam a maneira unidirecional de funcionamento de boa parte dos sistemas de informação, que devem ser preenchidos pelos municípios, mas poucos dados podem ser acessados em tempo adequado. Essa dificuldade de acesso contribui para que o uso da informação perca o sentido para o gestor municipal, e assuma um papel meramente burocrático, de alimentação do sistema por cobrança de instâncias superiores e para evitar a perda de recursos financeiros.

Além disso, o subuso ou a não utilização das informações contidas nos SIS podem estar vinculados à extensa carga de trabalho dos profissionais e ao grande número de sistemas de informação que devem ser preenchidos, mas que não interoperam entre $\mathrm{si}^{33,36}$. Apesar de o PlanejaSUS avançar na padronização dos documentos de planejamento, a alimentação dos seus dados depende de outros 
sistemas de informação que não operam em conjunto e, por isso, demandam tempo e habilidade para a busca de informação. Assim, no PlanejaSUS apesar da responsabilização dos gestores municipais pela alimentação regular dos SIS nacionais, há o reconhecimento de limites para definição e acompanhamento de algumas metas estabelecidas no Plano de Saúde, devido aos reais problemas de falta de dados nesses sistemas e também de sua heterogeneidade na cobertura e na qualidade, nas diferentes regiões de saúde ${ }^{32}$.

Os desafios apontados justificam a sugestão de criação de um sistema específico e unificado para formulação do planejamento, pois ainda existe a necessidade de melhorar o acesso, a organização e agregação de informações, de forma a facilitar a visão ampliada da realidade relacionada ao setor saúde nas regiões. Essa sugestão endossa a realização da gestão da informação de maneira eficiente, a partir de um conjunto de políticas que possibilite o provimento de informações relevantes, com qualidade suficiente, precisas e transmitidas ao local certo, no tempo apropriado, com custo adequado e que sejam acessíveis aos gestores ${ }^{16}$. Além disso, os gestores e técnicos devem ser capazes de acessar, avaliar e usar de forma ética a informação, destacando dentre os dados disponíveis aqueles que são mais relevantes para a tomada de decisões ${ }^{37}$. Nesse sentido, deve se ter em mente a necessidade de capacitação dos profissionais para tais atividades, em relação à aquisição de competência informacional no desenvolvimento das ações de planejamento em saúde $^{38}$. Essa constatação se deve ao fato de que os profissionais que assumem funções na gestão da saúde podem apresentar distintas formações acadêmicas e profissionais e também de que o investimento nas pessoas integra a gestão da informação em sua abordagem ecológica ${ }^{39}$.

Posteriormente ao acesso à informação, a necessidade de organizá-la levou ao aumento da crítica sobre as necessidades/demandas em saúde, devido ao processo de construção das ferramentas de planejamento. Esse achado corrobora a afirmação de Paim $^{40}$ de que esse processo, ao explicar objetivos e finalidades, pode colaborar para a redução da alienação dos gestores, técnicos e dos demais profissionais de saúde. Na prática, ao se apropriarem dessas informações, os gestores se tornam menos suscetíveis a pressão de políticas indutoras e midiáticas, como foi relatado em algumas falas, construindo o planejamento em consonância também com as suas realidades financeiras.

Após a organização das informações, seu uso na rotina da gestão é fundamental, para que não se caracterize um desperdício de tempo e de recursos ${ }^{41}$. Nesse sentido, os participantes apontaram apenas para tentativas de cumprimento das ações programadas, com enfoque na utilização das ferramentas no dia-a-dia da gestão ou, ao menos, na avaliação final do RAG, para que possam partir para novas programações. Entretanto, foram destacadas três grandes dificuldades para o uso das informações, sendo elas a pressão da mídia, a fragmentação da realidade em linhas de cuidado e a falta de cooperação federativa.

O relacionamento com a mídia tende a ser bastante complexo, uma vez que os órgãos de 
comunicação podem ter outros interesses, posições partidárias ou ideológicas não muito explícitas e trabalharem para atrair a atenção do público e de anunciantes. Sendo assim, a mídia pode se apresentar como uma ameaça, caso o papel da comunicação de massa seja menosprezado, ou como uma oportunidade, caso a comunicação seja competente. Para que este último aspecto seja efetivado se faz necessária uma política de comunicação eficiente, que contemple aspectos políticos e jornalísticos ${ }^{42}$. Além disso, para que o posicionamento do gestor frente à mídia e à população tenha credibilidade, é necessário usar informações que cumpram os atributos de confiabilidade, clareza e concisão ${ }^{34}$.

Outro aspecto, segundo os participantes, que dificultou a execução das ações planejadas e a própria organização das informações foi a fragmentação do planejamento em linhas de cuidado e o distanciamento entre os planejamentos dos entes federativos. Essa fragmentação tem sido característica do Estado brasileiro e a forma como se concretizam os seus processos decisórios, refletindo a implementação das políticas sociais de maneira atomizada e reativa ${ }^{21}$. Soma-se a isso a não aglutinação de informações, por problemas com os SIS e/ou entraves referentes às habilidades dos profissionais de saúde, que dificultam a apropriação da visão global do sistema, tanto dentro dos municípios como na RS. Essa fragilidade no planejamento deve ser contraposta com a melhora da capacidade de olhar o SUS de maneira sistêmica, que exige comprometimento e tempo, para que o pensamento sistematizado se torne frequente no cotidiano das práticas de planejamento municipais e regionais ${ }^{43}$. Além disso, exige melhora na cooperação federativa, para que de fato o planejamento seja ascendente e tenha como base as necessidades dos municípios.

Soma-se a essas dificuldades a falta de comunicação institucional, um empecilho na divulgação das informações e ao seu acesso quando fora dos SIS, sob o poder apenas de determinados indivíduos. As informações armazenadas possuem a capacidade de produzir conhecimento apenas a partir da ação de comunicação entre o estoque (fonte) e o receptor. Quem possui a propriedade sobre essa fonte acaba determinando sua distribuição e condiciona, posteriormente, a produção de conhecimentos $^{14}$. Além de não possibilitar a geração de conhecimento, essa falha de comunicação se torna um problema pelo não cumprimento das funções institucionais de disseminação de informações aos outros gestores e demais profissionais, dificultando o acesso dessas informações à sociedade, já que não há representantes de usuários dentro das CIR $^{18}$. Em contrapartida, a produção, o gerenciamento e a divulgação de informações são elementos estratégicos para o fortalecimento dos objetivos, das ações e da eficácia do planejamento e da gestão ${ }^{14}$.

Importante considerar o impacto dessa falta de comunicação à descontinuidade administrativa a cada troca de gestão. Isso se deve ao não compartilhamento de informações entre o representante do município e os demais participantes do processo de planejamento e da gestão que não frequentam as reuniões da CIR, condição que poderia caracterizar uma dinâmica de gerência centralizada $^{44}$. Essa descontinuidade mencionada pelos participantes também ocorre pelo não 
compartilhamento de informações entre os gestores do próprio município, após a descontinuidade referente à alternância de poder dos governos municipais. $\mathrm{O}$ armazenamento de informações em SIS, como o PlanejaSUS, vem contribuindo para uma menor perda de informações nessas trocas de governo, uma vez que os bancos de dados contêm informações explícitas, com potencialidade para dialogar com a subjetividade e conhecimento prévios de cada novo gestor, podendo ser transformadas em novos conhecimentos ${ }^{45}$.

Com a atual necessidade de assinatura do Contrato Organizativo da Ação Pública da Saúde $(\mathrm{COAP})^{8,46}$ pelos entes federativos, reforça-se a importância do uso de dados fidedignos para a realização do planejamento. Esse instrumento, resultante da gestão compartilhada, define entre os entes federativos as suas responsabilidades no SUS, permitindo uma organização direcionada às necessidades da RS, com diretrizes, metas e indicadores. $O$ contrato também garante o compartilhamento da gestão dotado de segurança jurídica. Entretanto, para que os gestores possam assumir essa responsabilidade se faz necessário o embasamento do planejamento em dados reais. As limitações apresentadas pelos entrevistados podem ser impeditivas para a assinatura do COAP.

\section{CONSIDERAÇÕES FINAIS}

Parte-se do entendimento de que a informação deva ser priorizada para a realização do planejamento em saúde e que, para tanto, deva existir uma política de seu gerenciamento. Ao construir o diálogo entre os atores sociais entrevistados, outros autores e as políticas de saúde afins, pôde-se notar que os participantes reconheceram a importância da gestão da informação e de seus atributos, porém relataram inconsistências dos dados nos SIS. Essa última constatação foi atribuída tanto à falta de formalização no processo de coleta e organização dos dados relacionada às características dos SIS (são numerosos e não se interoperam) quanto ao fator humano, ou seja, a necessidade de aquisição de competência informacional, pelos gestores e profissionais da área do planejamento, com implicações diretas na gestão da informação e no processo de planejamento em saúde.

Nesse sentido, o PlanejaSUS pretendeu ser um SIS auxiliar às questões de sistematização da coleta e da organização das informações direcionadas ao processo de planejamento. Certamente, esse sistema colaborou com o melhor reconhecimento acerca da realidade dos municípios, ao propor um método de abordagem da informação para o processo de planejamento, bem como, apresentou-se com um instrumento colaborador da continuidade administrativa por seu robusto repertório informacional. Em contrapartida, persistiram na ótica dos participantes, dificuldades para o seu uso, principalmente em relação a sua não interoperação com outros SIS.

Notou-se ainda, a dificuldade de emprego das informações nas ações de planejamento que pode ser caracterizada como um desperdício de tempo e de recursos. Além disso, deve-se investir na 
interlocução entre os gestores, incentivando a atuação responsável no espaço da CIR, com garantia do compartilhamento de informações, com vistas à produção de conhecimento e incremento da gestão da informação no contexto regional, para que seu uso possa ser estratégico no planejamento e na tomada de decisão.

Afirma-se que a CIR é caracterizada como um espaço potencial de encontro e de construção partilhada do planejamento locorregional do SUS, na perspectiva dos SIS e da gestão da informação em saúde. Entretanto, alguns desafios ainda devem ser transpostos para que haja fundamentação do planejamento regional em dados concretos, correspondentes à realidade dos municípios e da região de saúde, condição essencial para a concretização do COAP.

A pesquisa certamente não esgotou o assunto. Pode-se apontar como limitação do estudo a abordagem metodológica restrita à análise temática, sem a comparação com o conteúdo informacional dos instrumentos de planejamento das regiões de saúde estudadas. No entanto, ela contribui para a reflexão crítica, a partir do PlanejaSUS inserido no cenário político e gerencial da regionalização, na medida em que explicita avanços e debilidades na gestão da informação voltada ao processo de planejamento em saúde regional na CIR e suscita novas investigações acerca da temática.

\section{REFERÊNCIAS BIBLIOGRÁFICAS}

1. Brasil. Constituição (1988). Constituição da República Federativa do Brasil. Brasília, DF: Senado Federal; 1988.

2. Brasil. Lei $n^{\circ} 8.080$, de 19 de setembro de 1990. Dispõe sobre as condições para a promoção, proteção e recuperação da saúde, a organização e o funcionamento dos serviços correspondentes e dá outras providências. Diário Oficial da União 20 set 1990.

3. Brasil. Lei $n^{\circ} 8.142$, de 28 de dezembro de 1990. Dispõe sobre a participação da comunidade na gestão do Sistema Único de Saúde (SUS) e sobre as transferências intergovernamentais de recursos financeiros na área da saúde e dá outras providências. Diário Oficial da União 31 dez 1990.

4. Ministério do Estado da Saúde (Brasil). Norma Operacional Básica do Sistema Único de Saúde/SUS - NOB01/96. Diário Oficial da União 06 nov 1996.

5. Ministério do Estado da Saúde (Brasil). Portaria 95, de 26 de janeiro de 2001. Norma Operacional de Assistência à Saúde do Sistema Único de Saúde/SUS - NOAS01/01. Diário Oficial da União 29 jan 2001.

6. Ministério do Estado da Saúde (Brasil). Ministério da Saúde. Portaria no 399/GM, de 22 de ISSN 1982-8829 Tempus, actas de saúde colet, Brasília, 11(4), 123-145, dez, 2017. Epub Ago/2018 
fevereiro de 2006. Divulga o pacto pela Saúde 2006 e aprova as diretrizes operacionais do referido pacto. Diário Oficial da União 23 fev 2006.

7. Ferreira JBB. Avaliação do complexo regulador do sistema público municipal de serviços de saúde. Ribeirão Preto. Tese [Doutorado em ciência] - Escola de Enfermagem de Ribeirão Preto da Universidade de São Paulo; 2007.

8. Brasil. Decreto n 7.508 de 28 de junho de 2011. Regulamenta a Lei no 8.080/ 1990. Diário Oficial da União 29 jun 2011.

9. Ministério da Saúde (Brasil). Sistema de Planejamento do SUS (PlanejaSUS): instrumentos básicos/MS. Brasília: Ministério da Saúde; 2006. (Série Cadernos de Planejamento).

10. Mcgee JV, Prusak L. Gerenciamento estratégico da informação: aumente a competitividade e a eficiência de sua empresa utilizando a informação como uma ferramenta estratégica. Rio de Janeiro: Campus; 1994.

11. Siqueira MC. Gestão estratégica da informação. 1 ed. Rio de Janeiro: Brasport; 2005.

12. Capurro R, Hjørland B. O conceito de informação. Perspectivas em Ciência da Informação. 2007; 12(1).

13. Moraes IHS. Informações em saúde: da prática fragmentada ao exercício da cidadania. São Paulo: Hucitec; 1994

14. Carvalho ALB, Informação em saúde como ferramenta estratégica para a qualificação da gestão e o fortalecimento do controle social no SUS. Tempus - Actas de Saúde Coletiva. 2009; 3(3): 16-30.

15. Barreto AA. A questão da informação. Revista São Paulo em Perspectiva, Fundação Seade. 1994; 8(4).

16. Reis C. Planejamento Estratégico de Sistemas de informação. Lisboa: Presença; 1993.

17. Chaves E. Pilares da educação digital . Pilar 2: gerenciamento da informação [periódicos na internet].[s.d.]. Brasil [acesso em 10 out 2017]. Disponível em: http:// bibliotecadigital.fgv.br/ojs/index.php/rap/article/viewFi-le/7881/6550. 
18. Miranda SV, Streit RE. O processo de gestão da informação em organizações públicas. In: I Encontro de administração da informação, Enadi [evento na internet]. 2007 out 24-26; Florianópolis, Brasil [acesso em 10 set 2017]. Disponível em: http://www.anpad.org.br/admin/pdf/ enadi309.pdf

19. Carvalho ALB. A Gestão da Informação em Saúde e o Município: Um estudo sobre municípios que implantaram o Programa Saúde da Família e que estão integrados ao Projeto da Rede Estadual de Informação em Saúde REIS/RNIS-PB.Paraíba. Dissertação [Mestrado em Ciência da Informação] - Universidade Federal da Paraíba; 2004.

20. Braga A. A gestão da informação [periódicos na internet]. [s.d.] [acesso em 18 out 2017]; Disponível em: http://simagestao.com.br/wp-content/uploads/2016/04/Gestao-da-Informacao.pdf.

21. Moraes IHS, Gómez MNG. Informação e informática em saúde: caleidoscópio contemporâneo da saúde. Ciência \& Saúde Coletiva. 2007; 12(3):553-565.

22. Fekete, M. C. Planejamento e programação em saúde: bases conceituais e metodológicas do planejamento em saúde. Brasília: Ministério da Saúde; 2002. (Textos básicos).

23. Rivera FJU, Artmann E. Planejamento e gestão em saúde: histórico e tendências com base numa visão comunicativa. Ciênc. saúde coletiva. 2012; 15(5): 2265-2274.

24. Testa M. Pensamento estratégico e a lógica da programação. São Paulo: Hucitec; 1994.

25. Vieira FS. Avanços e desafios do planejamento no Sistema Único de Saúde. Ciênc. saúde coletiva. 2009; 14(Suppl 1): 1565-1577.

26. Marchiori PZ. A ciência e a gestão da informação: compatibilidades no espaço profissional. Ci. Inf., Brasília. 2002; 31(2):72-79.

27. Borges FQ. Gestão da informação no sistema único de saúde. R. Adm. FACES Journal Belo Horizonte. 2014, 13(2): 83-98.

28. Carvalho, ALB. Informação em saúde como ferramenta estratégica para a qualificação da gestão e o fortalecimento do controle social no SUS. Tempus - Actas de Saúde Coletiva. 2009; 3(3): 16-30.

29. Departamento de Informática do SUS [homepage na internet]. População estimada segundo município - Informações demográficas e socioeconômicas [acesso em 2017 agosto 25]. Disponível em: http://tabnet.datasus.gov.br/cgi/tabcgi.exe?ibge/cnv/poptsp.def. 
31. Junior JPB, Gesteira IAL. A ciência da informação e o controle social na área de saúde. In: CINFORM encontro nacional da ciência da informação [evento na internet]. 2004 jun 2830; Bahia, Brasil [acesso em 2017 ag 25]. Disponível em: http://www.cinform.ufba.br/v anais/ artigos/josebispojunior.html. [s.p.]

32. Ministério da Saúde (Brasil). Sistema de Planejamento do SUS (PlanejaSUS): uma construção coletiva - trajetória e orientações de operacionalização. Brasília: Ministério da Saúde; 2009. (Série B. Textos Básicos de Saúde)

33. Mota FRL. Registro de informação no sistema de informação em saúde: um estudo das bases SINASC, SIAB e SIM no Estado de Alagoas. Perspectivas em Ciência da Informação. 2009; 14(3): 238-239.

34. Sanches CS. Evolução das práticas ambientais em empresas industriais: um modelo genérico. In: Anais do IV Encontro Nacional sobre Gestão Empresarial e Meio Ambiente; 1997 nov 19-21; São Paulo, Brasil. São Paulo: Fundação Getúlio Vargas; 1997.

35. Vidor AC, Fisher PD, Bordin R. Utilização dos sistemas de informação em saúde em municípios gaúchos de pequeno porte. Rev. Saúde Pública. 2011; 45(1): 24-30.

36. Kierkegaard, P. Interoperability after deployment: persistent challenges and regional strategies in Denmark. International Journal for Quality in Health Care. 2015; 27(2): 147-153.

37. Zorrinho C. Gestão da Informação: Condição para Vencer. Lisboa: Iapmei; 1995.

38. Vitorino, EV, Piantola, D. Competência informacional - bases históricas e conceituais: construindo significados. Ci. Inf. 2009; 38(3): 130-141.

39. Davenport, T. Information ecology. New York: Oxford University Press; 1997.

40. Paim JS. Planejamento em saúde para não especialistas. In: Campo GWS et al. (Orgs.). Tratado de saúde coletiva. São Paulo: Hucitec; 2006: 767-782.

41. Gomes E. Gestão estratégica da informação [apresentação no I ciclo de palestras sobre gestão estratégica da informação; 2004 ag 09; Brasília, Brasil].

42. Sousa DL. Organização do sistema de referência para usuários do CEO saúde bucal de Itapipoca - CE. Projeto de Intervenção Escola de Saúde Pública do Ceará. Fortaleza: [s. n.]; 2009.

43. Senge PM. et. al. A Dança das Mudanças: os desafios de manter o crescimento e o sucesso em organizações que aprendem. 7. ed. Rio de Janeiro: Campus; 1999. 
44. Riviera FJU. Comunicação e gestão organizacional por compromissos. Revista de Administração Pública; 29(3): 211-230; 1995.

45. UNPAN, 2014 United Nations. United Nations E-government surve:. E-government for the future we want [manual na internet]. New York; 2014 [acesso em 20 set 2017]. Disponível em: https://publicadministration.un.org/egovkb/Portals/egovkb/Documents/un/2014-Survey/EGov_Complete_Survey-2014.pdf

46. Comissão Intergestores Tripartite (Brasil). Resolução no 5, de 19 de junho de 2013. Dispõe sobre as regras do processo de pactuação de Diretrizes, Objetivos, Metas e Indicadores para os anos de 2013-2015, com vista ao fortalecimento do planejamento do SUS e a implementação do COAP. Diário Oficial da União 20 jun 2013.

Artigo apresentado em 30/11/17

Artigo aprovado em 02/02/18

Artigo publicado no sistema em 31/08/18 